Research Article

\title{
Research on the Impact Mechanism and Application of Financial Digitization and Optimization on Small- and Medium-Sized Enterprises
}

\author{
Qiuxia Li (iD) \\ Renmin University of China, 100872 Beijing, China \\ Correspondence should be addressed to Qiuxia Li; changfeng326@163.com
}

Received 2 September 2021; Accepted 12 October 2021; Published 29 October 2021

Academic Editor: Punit Gupta

Copyright (c) 2021 Qiuxia Li. This is an open access article distributed under the Creative Commons Attribution License, which permits unrestricted use, distribution, and reproduction in any medium, provided the original work is properly cited.

\begin{abstract}
Background. With the continuous advancement of digital technology and the accelerated development of digital finance, the rise of digital finance has had a vital impact on the true evolution of SMEs. The digital economy has a significant positive impact on the productivity of SMEs. Method. This article first analyzes the digital level of SMEs, studies the incentive effect of digital finance on the level of technological revolution of SMEs, and analyzes the mitigation effect of digital finance evolution on the financing constraints of SMEs. At the same time, it also studies how to develop the digital economy and achieve high-quality business evolution. Result. The digital economy can promote the growth of enterprise productivity through four indirect ways: scale economy effect, scope economy effect, technological revolution effect, and management benefit effect. Conclusion. The Financial Technology Optimization program helps financial leaders adopt new digital technologies to optimize financial processes while minimizing disruption.
\end{abstract}

\section{Introduction}

The deep incorporation of new generation of Internet of Things, big data, Tencent Cloud computing, artificial intelligence, blockchain, and traditional industries has made commercial and social evolution move towards networking, digitization, and intelligence and gradually formed a new form of digital economy. Digital finance has the attribute of low financing cost, high effectiveness, and free from time and space constraints, so it has attracted wide attention of the society. SMEs, with its unique volume advantage, are not only an important driving force for commercial growth but also the backbone of technological revolution. Financial technology has shown great evolution potential and space [1-3]. The rapid evolution of financial technology can alleviate information asymmetry and broaden the scope of financial services. All sectors of society in China are very concerned about the evolution of SMEs because SMEs can play an important role in promoting commercial growth, stimulating market vitality, promoting scientific and technological progress, and expanding employment. There has been a phenomenon that the concept is greater than action in the evolution of digital finance because digital inclusive finance is faced with global common problems such as high cost, low effectiveness, and unbalanced service $[4,5]$. How to balance policy support and market evolution is quite difficult.

Digital finance refers to various and significant commercial activities that utilize digital knowledge and information as critical production factors, state-of-the-art information network as a critical carrier, and the effective use of information and communication technology as an important driving force for effectiveness improvement and commercial structure optimization. The impact of digital economy on productivity is closely related to the evolution of information technology. Digital finance can curtail the related costs, solve the problem of information asymmetry, and provide the ability to predict threats through the application of intelligent technologies such as computer technology, data communication, big data analysis, and cloud computing in the financial field. Compared with traditional nondigital services, digital finance can better 
provide appropriate and effective financial services for SMEs at affordable costs. With the continuous revolution of digital technology and the booming popularity of digital economy, digital finance has become the only way for financial evolution. Digital technology provides solutions to overcome financial difficulties. The digital platform can evaluate the credit threat of hundreds of millions of users through big data analysis technology, which greatly curtails the cost of customer threat control and improves the feasibility of inclusive financial evolution. Digital finance is the deepening of inclusive finance, and inclusive finance must develop in the direction of digital finance. Research on the evolution of digital finance has certain practical significance for the evolution of SMEs. The stability structure of China's financial science and technology has basically formed, the incorporation of underlying technologies has accelerated, and the application pilot has continued. The blockchain industry has ushered in a new round of growth, which provides a strong impetus for commercial evolution. Therefore, studying the conjunction between digital finance and SMEs has an important guiding role and practical significance for the government to innovate the local financial market environment and formulate the financial evolution strategy of SMEs.

\section{Materials and Methods}

The state attaches great importance to the evolution of revolution and entrepreneurship activities and has issued many policies to encourage the public to actively carry out revolution and entrepreneurship activities. However, since revolution and entrepreneurship require substantial financial support, most SMEs face varying degrees of financing difficulties in the early stages of entrepreneurship. In this context, the birth of digital finance has brought new hope to the financing of SMEs. By constructing the index of technological and financial evolution level of SMEs, it is found that financial technology can increase enterprise revolution by alleviating the financing constraints of SMEs and improve the revolution effect of government tax return. In the new era, the rapid incorporation of big data technology and financial activities and the deep incorporation of information technology and financial industry have promoted the evolution of financial science and technology, a new type of financial industry, greatly changed the traditional financial service mode, and broken many restrictions on traditional financial services. In the R\&D stage of technological revolution in SMEs, enterprises will carry out research and evolution, test new technologies or new products with great uncertainty, face high technical threats, and need a lot of human capital and fixed equipment investment. Enterprises need the support of revolution threat capital, so at this stage, financing constraints will have a significant impact on technological revolution of SMEs [6-8]. The evolution of digital finance can alleviate the financing constraints of SMEs, and the level of commercial evolution and legal environment are important factors restricting digital finance to alleviate the financing constraints of SMEs. Digital finance can give full play to the advantages of low cost, high speed, and wide coverage through scenarios and data, curtail the threshold and cost of financial services, improve the financing environment of SMEs [9], and more effectively serve inclusive financial entities. The level of financial evolution is one of the key factors because in the underdeveloped financial market, enterprises will face higher external financing costs, and a good financial evolution environment will help ease the financing constraints faced by enterprises. Digital inclusive finance is the deepening of inclusive finance $[10,11]$. The combination of data and financial revolution products more effectively curtails the information asymmetry between capital reservoir and demand and more significantly curtails the threshold and cost of financial services [12, 13]. Therefore, digital inclusive finance can ease the financing constraints of SMEs.

The impact mechanism of financial evolution on technological revolution: on the one hand, some scholars believe that financial evolution may encourage SMEs to achieve technological revolution by opening trade or reducing transaction costs, easing financing constraints of SMEs, and loosening R\&D capital investment [14]. On the other hand, some scholars believe that the attribute of technological revolution projects, such as high investment and long cycle, make small- and medium-sized innovative enterprises have a strong dependence on external financing. Countries (regions) with a sound financial market system and high level of financial evolution will optimize the allocation of financial resources, reasonably guide the flow of funds, and curtail the problem of information asymmetry. The indirect mechanism of the influence of the digital economy on enterprise productivity is shown in Figure 1. With the commercial society moving from the industrial economy era to the digital economy era, the traditional way of achieving performance growth through factor expansion is difficult to meet the needs of high-quality evaluation of enterprises $[15,16]$. Under this background, enterprises realize the automation and intelligence production and service through a digital transformation, curtail the dependence on labor, directly curtail the production cost, and improve the production effectiveness $[17,18]$. The indirect mechanism of the digital economy on the productivity of small and medium enterprises is shown in Figure 1. At the same time, the data resources generated by the digital transformation of enterprises can not only participate in the production process as production factors together with capital, labor, and other resources, directly driving productivity growth, but also improve the utilization effectiveness and allocation effectiveness of traditional production factors such as capital and labor, thus improving the productivity of enterprises.

In the new era, the accelerated incorporation of big data technology and financial activities and the deep incorporation of information technology and financial industry have promoted the evolution of digital finance, a new type of financial industry, which has greatly changed the traditional financial service model and broken many limitations of traditional financial services. First of all, due to its own limitations, traditional financial institutions are generally difficult to penetrate into financially poor areas. As a product of the combination of digital technology and finance, digital 


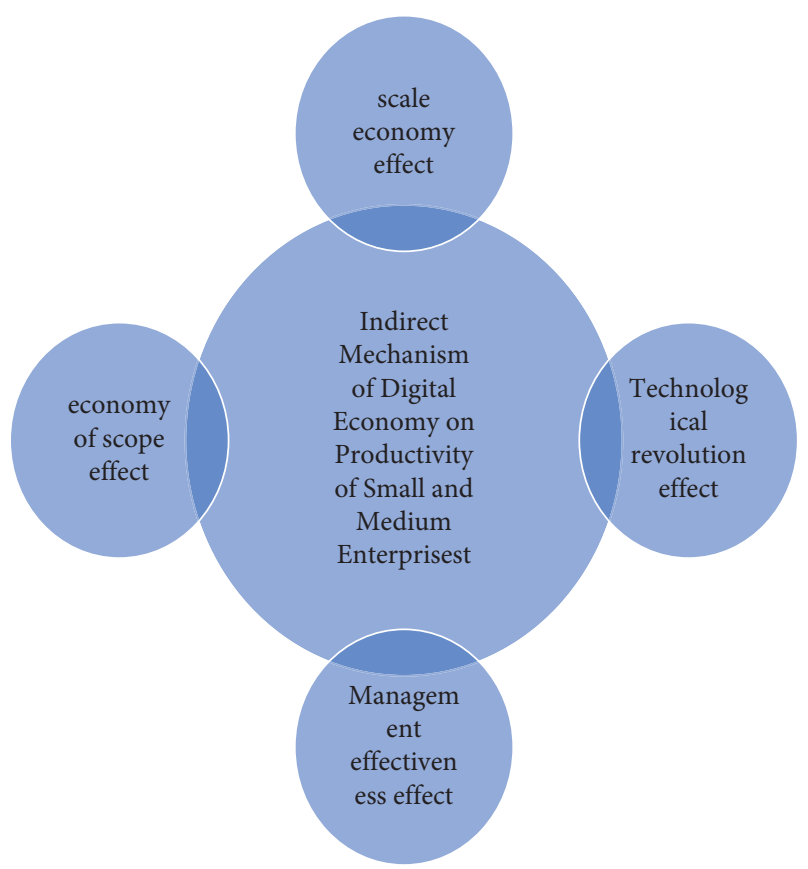

Figure 1: The indirect mechanism of the influence of digital economy on enterprise productivity.

finance has strong geographical penetration, breaks the time and space constraints, and can participate in financial activities anytime and anywhere to improve the availability of financial services. With the breakthrough evolution of science and technology revolution, the coverage of digital finance will be further expanded, which can curtail the financing cost of SMEs, greatly alleviate the financial exclusion faced by SMEs, and provide financial support for the technological revolution of SMEs. The influence mechanism of digital finance on small and medium enterprises is shown in Figure 2. Secondly, financial science and technology can fully understand SMEs based on big data analysis, improve enterprise information transparency, alleviate information asymmetry between financial institutions and SMEs, curtail adverse selection and moral hazard, transform resources in the market into effective reservoir, curtail resource, optimize resource allocation, and provide necessary conditions for improving technological revolution of SMEs. First, digital finance enables SMEs to obtain the same market opportunities as large enterprises, helps them establish market credit, and improves sales revenue. The third is to promote the internal information construction of enterprises, improve the standardization and effectiveness of management, and curtail the management cost of SMEs. The fourth is to make the revolution of products and services become the key to win the market competition and improve the revolution consciousness of SMEs. The increase and diversity of consumption create market opportunities for SMEs.

Digital finance can promote the technological revolution of SMEs by promoting e-commerce, affecting the total consumption and structure, easing financing constraints and technology spillover. The empirical results show that the evolution of digital finance in China significantly promotes the technological revolution of SMEs, and the influence mechanism is as follows: first, digital finance improves the profitability of enterprises by increasing sales revenue and reducing management costs. Second, by reducing the cost of borrowing and improving the structure of borrowing, digital finance makes the structure of enterprise borrowing longterm and eases the credit constraints of enterprises. Third, the payment, monetary fund, insurance, credit, and other business functions of digital finance have significantly promoted the technological revolution of enterprises. In addition, the classification study found that the evolution of digital finance in China is very uneven among regions, especially in the central and western regions.

\section{Results}

China's complete industrial system is supported by the industrial chain cluster composed of large- and mediumsized enterprises and small enterprises with meticulous division of labor, professional, and orderly. In the reservoir chain of the industrial chain cluster, it is inevitable that the core large enterprises monetize their dominant position in the market, such as extending the accounting period, which leads to the shortage of funds for SMEs. Digital finance focuses on the confirmation of core enterprise contracts or commercial bills in the reservoir chain. With the help of blockchain technology, it can cover the multilevel enterprises in the reservoir chain and solve the liquidity replenishment problem of some SMEs. The evolution of digital finance also makes it possible to build a public credit information platform for SMEs. The public credit information platform can not only get through all kinds of scene data but also cooperate with all kinds of financial institutions to develop models, investment, and loan linkage and provide SMEs with life-cycle training, guidance, and financing intermediary services, as shown in Figure 3. Digital technology improves the revolution ability of SMEs, and the improvement of technological revolution level is one of the main ways to improve productivity. In the R\&D mode, the open digital R\&D management system helps SMEs turn from the traditional closed revolution mode to the open revolution mode with the participation of all departments, even the whole industry chain and the whole society, so that R\&D and design activities can be carried out in a multidimensional collaborative network, to realize integrated and networked revolution and improve enterprise revolution ability. In the R\&D process, digital design tools such as digital twin and digital simulation can accurately simulate various physical parameters of physical entities and display them in a visual way, to achieve $\mathrm{R} \& \mathrm{D}$ revolution in a variety of scenarios in a dynamic and uncertain environment and improve the accuracy of R\&D. Digital finance can provide financial basis for revolution activities and create more entrepreneurial opportunities. Information technology is an important factor to promote the evolution of business model. Internet big data technology has greatly weakened the cost in search, evaluation, transaction, and other aspects, making great changes in the traditional business model. Digital finance breaks the space limitation of traditional transactions, enables businesses and consumers to trade 


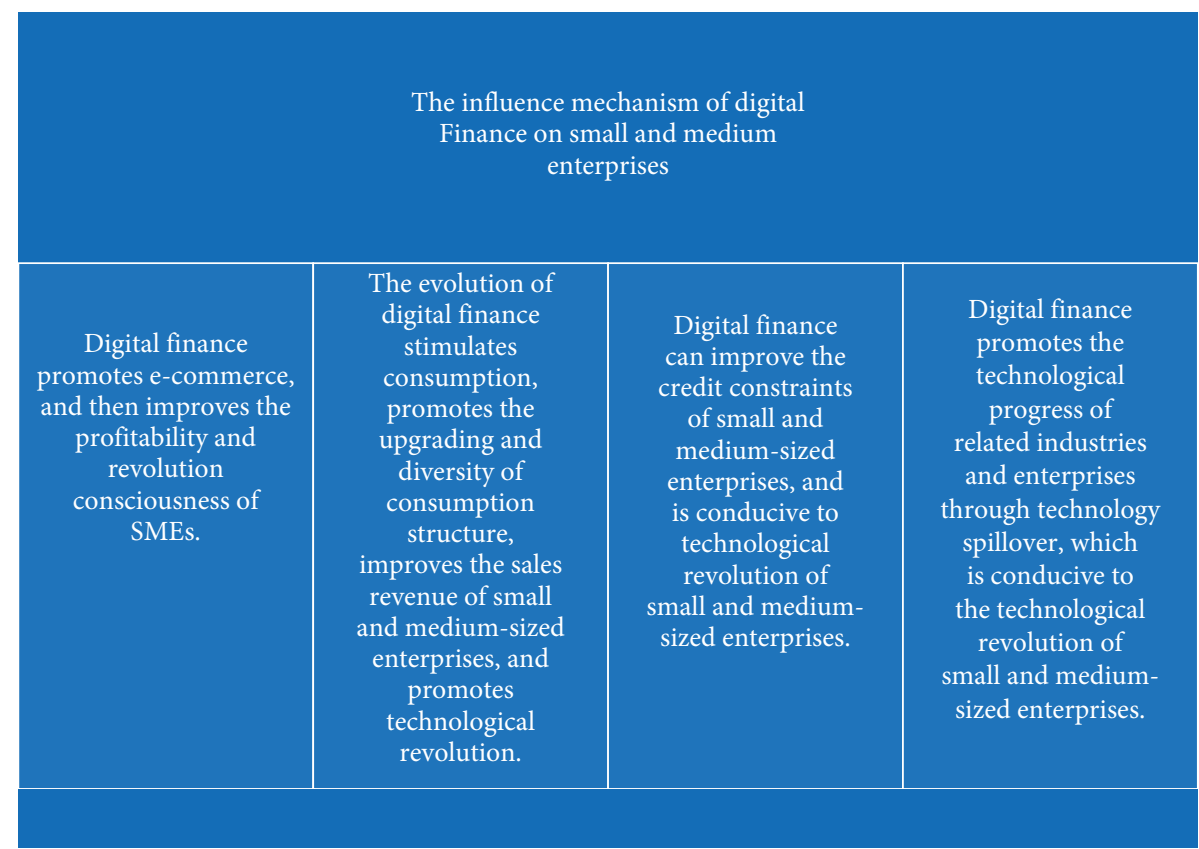

Figure 2: The influence mechanism of digital finance on small and medium enterprises.

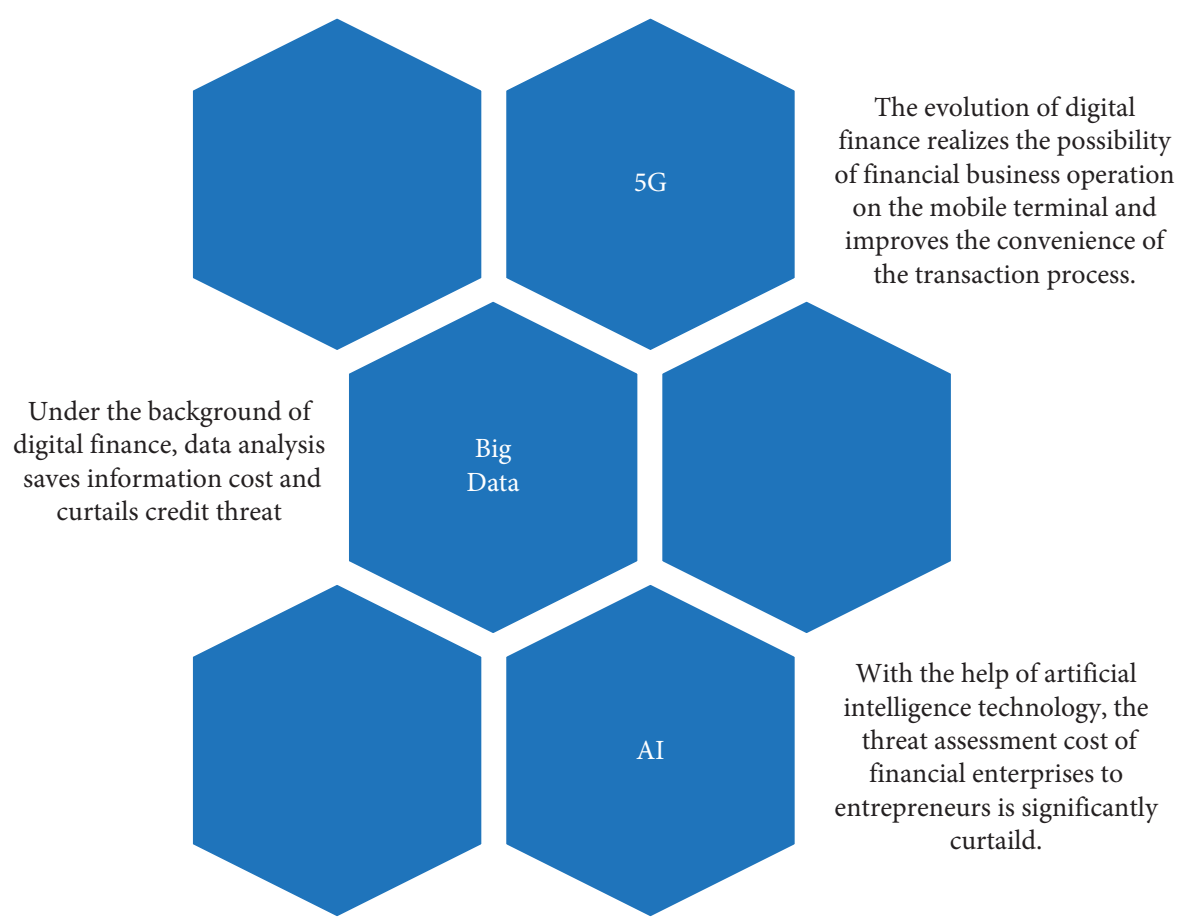

FIgURE 3: Some common technical applications of digital finance.

online, curtails the financial delivery link in the traditional business model, and improves the effectiveness of financial transactions. Similarly, taking Alipay as an example, the appearance of Alipay changed the way of payment and promoted the evolution of e-commerce. It laid the foundation for the transformation of traditional financial business. The evolution of online car hailing, bike sharing, and other fields all benefit from the evolution of digital payment technology. It can be seen that digital finance is of great significance to promote revolution and create employment opportunities for SMEs. The role of digital finance in promoting SMEs makes up for the problem that traditional financial institutions cannot take care of backward SMEs and self-employed households, which can affect the effective evolution of local revolution and entrepreneurship activities to a large extent. The transformation and upgrading of industrial chain not only needs the high-quality evolution of SMEs but also needs the coordinated evolution of industrial 
clusters. Therefore, it is necessary to build an "industrial digital finance" consortium, aggregate the real industry, finance, science, and technology, build an ecological community, based on the industrial chain and industrial ecology, relying on the industrial Internet platform and financial service platform, deeply integrate the industrial chain, revolution chain, and capital chain, and jointly serve and empower the industrial cluster. In this ecological community, finance should play the role of an accelerator. Based on various scenarios of the industrial chain, it should provide science and technology support, data penetration, financial matching for the industry, empower the entity enterprises, and realize the improvement of production effectiveness, product revolution, and service upgrading. For example, through bill settlement and payment settlement platform, digital finance can improve the effectiveness of capital turnover in industrial clusters and provide comprehensive financial services of "stock debt loan investment" for the scale expansion of core leading enterprises. Furthermore, we should provide SMEs in the chain with financing products such as "order loan" to solve the problem of capital turnover.

The high-quality evolution of SMEs is an important guarantee to promote high-quality commercial evolution. The central government attaches great importance to the revolution and evolution of SMEs and puts forward higher requirements for financial support to SMEs. In particular, facing the COVID-19 pandemic, protecting small and medium enterprises is to ensure employment. Protecting employment is to protect people's livelihood. SMEs need financial support. The emergence of digital finance provides new financing channels for the revolution and evolution of small and microenterprises and provides an effective means for small and microenterprises to balance revolution and evolution, prevent, and resolve financial threats.

\section{Conclusion}

In the critical period of the transformation of new and old kinetic energy, we should continue to strengthen the construction of relevant financial infrastructure, give certain policy support to SMEs, increase investment in 5G, big data, cloud computing, blockchain, and other fields, improve the ability of independent research and evolution of technology, and promote the integrated evolution of digital technology and financial market. At the same time, we should strengthen the precise support for SMEs and private enterprises, realize one-to-one docking, establish a diversified financial system, provide rich and high-quality financing channels, provide enterprises with lower cost and more convenient financial services, and fully release the vitality of financial technology to promote technological revolution and commercial growth. Digital finance has a significant role in promoting the financing of SMEs and individual entrepreneurs, which can effectively curtail the financing threshold and improve the financing availability of entrepreneurs. It also helps to curtail part of the financing cost and improve the utilization rate of resources. In order to further strengthen the application effectiveness of digital finance in the field of entrepreneurship, in addition to improving the corresponding laws and regulations, we should speed up the construction of a reasonable digital financial system, build professional entrepreneurial digital financial institutions, pay attention to the revolution of the market and the improvement of the order, and provide the most basic guarantee for the entrepreneurship of all kinds of main bodies in China.

\section{Data Availability}

Data sharing not applicable to this article as no datasets were generated or analysed during the current study.

\section{Conflicts of Interest}

The author declares no conflicts of interest.

\section{References}

[1] U. Marjanovic, S. Rakic, and B. Lalic, "Digital servitization: the next "big thing" in manufacturing industries," IFIP Advances in Information and Communication Technology, vol. 56, no. 11, pp. 510-517, 2019.

[2] S. D. Oliner, D. E. Sichel, and K. J. Stiroh, "Explaining a productive decade," Journal of Policy Modeling, vol. 30, no. 4, pp. 633-673, 2008.

[3] A. Philippe and H. Peter, "Joseph Schumpeter lecture appropriate growth policy: a unifying framework," Journal of the European Commercial Association, vol. 4, no. 2, pp. 269-314, 2006.

[4] H. Jiang and Y. Liu, "Digital finance, reservoir chain finance and corporate financing constraints: empirical evidence from listed companies on SME Board," Research on technology economy and management, vol. 3, pp. 73-77, 2021.

[5] F. Zhao, "Financial technology and high quality commercial evolution: evidence from provincial level," Financial economy, vol. 3, pp. 9-18, 2021.

[6] T. Wu and R. Wang, "Digital finance, bank competition and bank threat-taking: a study based on 149 small and mediumsized commercial banks," Journal of Finance and commercials, vol. 3, pp. 38-48, 2021.

[7] W. Huang, "Promoting industrial digital connection and building digital financial ecology -- thinking and practice of financial technology revolution of China Guangfa bank," China financial computer, vol. 3, pp. 20-22, 2021.

[8] S. Pan, D. Ye, and Y. Xian, "Is digital finance inclusive? empirical evidence from urban revolution," Economist, vol. 3, pp. 101-111, 2021.

[9] Q. Wu and Y. Zhu, "Research on the impact of digital inclusive finance on enterprise technological revolution identification of stage mechanism and analysis of heterogeneity," Industrial technology economy, vol. 40, no. 3, pp. 143-151, 2021.

[10] J. Jia and Y. Liu, "Digital finance, executive background and enterprise revolution: empirical Evidence from listed companies on SME board and gem," Finance and Trade Research, vol. 32, no. 2, pp. 65-76 + 110, 2021.

[11] C. Du and Y. Zhang, "Research on the influence mechanism of digital economy evolution on enterprise productivity growth," Securities market guide, vol. 2, pp. 41-51, 2021.

[12] C. Cui and L. Zhao, "The evolution and influence of digital inclusive finance," China's national conditions and strength, vol. 2, pp. 8-10, 2021. 
[13] L. Li and W. Tian, "Digital financial evolution, industrial structure transformation and regional commercial growth: an empirical analysis based on spatial durbin model," Financial Theory and Practice, vol. 2, pp. 8-16, 2021.

[14] A. Chinnasamy, B. Sivakumar, P. Selvakumari, and A. Suresh, "Minimum connected dominating set based RSU allocation for smartCloud vehicles in VANET," Cluster Computing, vol. 22, no. 5, pp. 12795-12804, 2019.

[15] H. Zou and Y. Huang, "Research on the effect of digital Inclusive Finance Evolution on regional revolution effectiveness," Finance and economy, vol. 1, pp. 48-55, 2021.

[16] Y. Zhou, "The role and Countermeasures of digital Inclusive Finance in promoting the evolution of small and micro enterprises," Financial journal, vol. 1, pp. 24-31, 2021.

[17] S. Feng and Q. Song, "The impact of digital finance evolution on the quality of life of Chinese residents," Commercial and management review, vol. 37, no. 1, pp. 101-113, 2021.

[18] Sivakumar, S. Prasanna, S. Hemalatha, and B. Sivakumar, “A harmonized trust assisted energy efficient data aggregation scheme for distributed sensor networks," Cognitive Systems Research, vol. 56, pp. 14-22, 2019. 